\title{
Territorialidad y socialidad en los movimientos sociales latinoamericanos: una aproximación al estudio del MST de Brasil y del MOCASE de Argentina*
}

\author{
Lázaro M. BACALLAO-PINO \\ Instituto de la Comunicación e Imagen - Universidad de Chile \\ Programa FONDECYT (Chile) \\ lazaro_bacallao@biari.brown.edu
}

Recibido: 24-11-2014

Aceptado: 29-04-2015

\begin{abstract}
RESUMEN
La (des)territorialización ha sido uno de los principales ejes de análisis en torno a los procesos globalizadores en las sociedades contemporáneas, sobre todo en aproximaciones a la cuestión desde sus dimensiones cultural-identitarias. Este artículo, basado en un estudio de casos de movimientos sociales latinoamericanos ligados al contexto rural, discute las articulaciones entre los procesos contrahegemónicos de apropiación de la territorialidad y las dinámicas de emergencia de una nueva socialidad que se desarrollan como parte de la acción colectiva. Estos vínculos, así como las diversas mediaciones que los atraviesan, evidencian la complejidad de los nuevos sentidos de la territorialidad configuradas por estos movimientos, no limitados a la cuestión propietario-espacial, sino que apuntan a proyectos de cambio social. Se concluye que en los movimientos analizados hay una mediación mutua y compleja entre apropiación de territorialidades y emergencia de nuevas socialidades, en una articulación intermediada por dimensiones como la comunicación y la ritualidad.
\end{abstract}

Palabras clave: movimientos sociales; América Latina; socialidad; territorialidad; cambio social.

\section{Territoriality and Sociality in Latin American Social Movements: An Approach to the Study of MST in Brasil and MOCASE in Argentina}

\section{ABSTRACT}

Des-territorialization has been one of the dimensions for the analyses of globalization processes in current societies, mainly from the identity-cultural dimension of the phenomenon. A multiple case study of two Latin American social movements - particularly those acting from rural context- shows the articulations

\footnotetext{
${ }^{*}$ El autor agradece los atinados comentarios de los evaluadores, a partir de los cuales se han logrado mejoras en el desarrollo del texto y en la exposición de ideas. También agradece al Proyecto de Postdoctorado Núm. 3150063, del Fondo Nacional de Desarrollo Científico y Tecnológico (FONDECYT) de Chile.
} 
between the counter-hegemony processes of appropriation of territoriality developed as part of the collective action. These links, as well as the diverse mediations mediating them, demonstrate the complexity of the new senses of territoriality created by these social movements, which overcome the property and the spatial dimension and are directly connected with processes of social change. We conclude that there is, in the both movements analyzed, a mutual and complex mediation between appropriation of territorialities and emergence of new sociabilities, in an articulation mediated by dimensions such as communication and rituals.

Key words: social movements; Latin America; sociability; territoriality; social change.

\title{
Territorialidade e sociabilidade nos movimentos sociais latino- americanos: uma aproximação ao estudo do MST do Brasil e do MOCASE da Argentina
}

\begin{abstract}
RESUMO
A (des)territorialização tem sido um dos principais eixos analíticos sobre os processos globalizantes nas sociedades contemporâneas, especialmente em aproximações que consideram as dimensões culturais e identitárias. Este artigo, baseado em um estudo de casos de movimentos sociais latino-americanos ligados ao contexto rural, discute as articulações entre os processos contra-hegemônicos de apropriação da territorialidade e as dinâmicas de emergência de uma nova sociabilidade desenvolvida como parte da ação coletiva. Estes vínculos, bem como as mediações intrínsecas aos mesmos, evidenciam a complexidade dos novos sentidos da territorialidade configuradas por estes movimentos, não limitados à questão proprietário-espacial, mas configurados ao redor de projetos de mudança social. Conclui-se que nos movimentos analisados existe uma mediação mutua e complexa entre apropriação de territorialidade e emergência de novas sociabilidades, em uma articulação intermediada por dimensões como a comunicação e o ritual.
\end{abstract}

Palavras-chave: movimentos sociais; América Latina; sociabilidade; territorialidade; mudança social.

REFERENCIA NORMALIZADA

Bacallao-Pino, Lázaro M. (2014) "Territorialidad y socialidad en los movimientos sociales latinoamericanos: una aproximación al estudio del MST de Brasil y del MOCASE de Argentina". Geopolítica(s). Revista de estudios sobre espacio y poder, vol. 5, núm. 2, 231-252.

SUMARIO: Introducción. 1. Material y método. 2. Movimientos sociales latinoamericanos: apropiación de la territorialidad desde nuevas socialidades. 3. MST: tierra, reforma agraria y cambio social. 4. MOCASE: un nuevo modelo agrario y de país. Conclusiones. Bibliografía.

\section{Introducción}

La territorialidad ha sido uno de los ejes analíticos en torno al proyecto de modernidad capitalista. La noción de territorio ha evolucionado, desde un concepto referido al espacio hacia una categoría densa (Achkar, 2003), transitando de una definición estatal de la espacialidad y del territorio, hacia una noción de territorio transnacionalizado (Santos, 1994). A partir del último cuarto del siglo XX, el territorio co- 
mienza a perder su anterior condición de objeto concreto y pensado, unificador de acciones e integrador de niveles, dimensiones, temporalidades y espacialidades (Bozzano, 2000).

La territorialidad no solo está asociada a distribuciones y espacialidades, sino también a las relaciones sociales de poder. La vinculación entre territorialidades y socialidades se fundamenta en los procesos de construcción de sentidos compartidos, mediante dinámicas culturales, comunicativas e identitarias. Nociones como la de "comunidades imaginadas" (Anderson, 1991), apuntan a la configuración de territorialidades de sentido. El territorio es entendido como el producto espacial de una determinada relación social, la territorialidad, en tanto que estrategia individual o grupal para afectar, influir o controlar a los individuos, fenómenos y sus relaciones a través de la delimitación y el control sobre un territorio (Sack, 1986).

Durante la mayor parte del siglo XX, la geografía política se centró en el Estadonación como espacio territorial hegemónico, pero a partir de los años 80, aparecen propuestas que cuestionan esta perspectiva, planteando que el territorio se define a partir de una multiplicidad de escalas (Raffestin, 1993). Desde América Latina, se plantea que los territorios no pueden ser reducidos a la escala del Estado-nación, al existir y ser (de)construidos en diferentes escalas y temporalidades (Lopes de Souza, 1995). A partir de un análisis latinoamericano, Agnew y Oslender (2010) proponen la noción de "territorialidades superpuestas" para cuestionar la vinculación entre territorialidad y soberanía del Estado-nación y plantear la existencia de otras fuentes de autoridad territorial distintas de la estatal, a partir de la disputa de actores no estatales, entre los cuales se destacan, precisamente, los movimientos sociales.

El tránsito del espacio de los lugares al de los flujos, propio de la sociedad red (Castells, 1999) implica ciertos procesos de desterritorialización en las sociedades contemporáneas. Esta desterritorialización ha sido asociada a una homogeneización cultural global, destructora de las culturas locales (LaFeber, 1999) y a la emergencia de comunidades virtuales - gracias a las tecnologías de la información y la comunicación (TIC) - , desvaneciendo la noción de territorio físico de las comunidades (Krause, 2001). Se plantea la "desterritorialización de las identidades" (García Canclini, 1989, 2001) y la vivencia cultural actual se define como un "evento multicultural y desterritorializado" (Brünner, 1998). Otros autores han señalado que, en realidad, los análisis sobre la noción de "desterritorialización" están atravesados por imprecisiones y malentedidos, pues en realidad estarían haciendo referencia a "una movilidad cada vez mayor y, cuando hablan de la cultura, de un hibridismo de la territorialidad en sentido cultural", dando cuenta de la emergencia de unos nuevos "territorios-red, o redes que reúnen múltiples territorios" y la "a la intensificación del fenómeno de la multiterritorialidad" (Haesbaert, 2013: 12).

Pero simultáneamente también se producen "fuertes movimientos de reterritorialización", que precisamente tendrían entre sus escenarios principales a movimientos sociales que afirman lo local, ligados al espacio de la cultura histórico-territorial (García Canclini, 2001). De hecho, frente a las perspectivas que vincu- 
lan la globalización al desanclaje creciente de las relaciones sociales de sus contextos socio-territoriales, Brenner (1999: 431) considera que "los procesos de reterritorialización - la reconfiguración y re-escalamiento de las formas de organización territorial como las ciudades y los Estados- constituyen un momento intrínseco del actual globalización". La asociación entre (alter)globalización y movimientos sociales - al punto de ser considerados una dimensión central de la configuración del nuevo orden social (Castells, 1999) -, reafirma esta vinculación entre tales actores sociales y esos procesos de reterritorialización. En tal sentido, resulta relevante una indagación en torno a estos procesos de reterritorialización que tienen lugar desde tales actores colectivos, sobre todo en el contexto latinoamericano, caracterizado por la creciente presencia e importancia de los movimientos sociales como actores sociopolíticos (Sader, 2008). Durante la última década del siglo XX, el continente fue escenario de la emergencia y expansión del denominado movimiento alterglobalización: desde el levantamiento zapatista en 1994; el primer Foro Social Mundial (FSM) de Porto Alegre en 2001; las movilizaciones de pueblos originarios en países como Ecuador y Bolivia, con particular fuerza entre 2000 y 2003; o el estallido social en Argentina, en diciembre de 2001. La realidad latinoamericana ha estado marcada por un sostenido incremento de la conflictividad social, manifiesto en un nuevo ciclo de protestas sociales que "aparece encarnado en sujetos colectivos con características particulares y diferentes de aquellos que habían ocupado la escena pública en el pasado" (Seoane et al., 2006: 228-229).

Durante la última década y media, los movimientos sociales latinoamericanos han protagonizado numerosos episodios de movilización social, como parte de sus repertorios de acción colectiva (Tarrow, 1994; Tilly, 1995), cuyo inventario mínimo incluiría la Guerra del Agua en Bolivia (2000); las movilizaciones indígenas en Ecuador (2000); las movilizaciones en Argentina (2001-2002); la Guerra del Gas en Bolivia (2003); las protestas estudiantiles en Chile (2006 y 2011) o las movilizaciones del \#YoSoy132 en México (2012). También se han configurado espacios y estrategias regionales de resistencia e intercambio de experiencias, como las Cumbres de los Pueblos de América y se han desplegado campañas continentales, como la Campaña contra el ALCA (Área de Libre Comercio de las Américas).

En este contexto, el objetivo del artículo es examinar la articulación entre procesos de apropiación territorial y emergencia de nuevas socialidades, en dos movimientos sociales rurales latinoamericanos: el Movimiento Sin Tierra (MST) de Brasil y el Movimiento Campesino de Santiago del Estero (MOCASE), de Argentina. Son movimientos analíticamente significativos pues comparten una vocación por el cambio social, que se expresa en novedosas prácticas y relaciones sociales (Zibechi, 2003) y su emergencia está ligada a procesos de desterritorialización de los trabajadores del campo durante los 80 en ambos países. El MST y el MOCASE se instalan en el contexto del debate sobre territorialidad, desterritorialización y reterritorialización (Herner, 2009), que ha tenido en las comunidades locales rurales uno de sus escenarios de tensión desde la década del 90, como parte de los juegos 
de acción y reacción entre las dimensiones global y local (Entrena Durán, 1999). Además, su condición multidimensional — su dualidad local y global, así como su reticularidad (Riechman y Fernández Buey, 1995)—, los vincularía a la multiterritorialización, entendida como la posibilidad - actualmente exacerbada- de experimentar diferentes territorios simultáneamente (Haesbaert, 2007).

En el caso del MST, la "modernización dolorosa" brasileña de los años 70 - mecanización e introducción de formas más capitalistas y modernas en la agricultura-, significó la expulsión del campo de grandes contingentes de población que "los obligó a tomar dos decisiones: tratar de resistir en el campo y buscar otras formas de lucha más acordes con las regiones donde vivían" (Stedile, en Mançano, 2001: 2-3). Desde su emergencia, este movimiento asume tres reivindicaciones prioritarias: la conquista de la tierra, la Reforma Agraria y un cambio radical de las estructuras y relaciones sociales (Harnecker, 2002).

Esta apertura hacia lo social distingue al MST de los movimientos campesinos tradicionales, conectando a su vez con la necesidad de encontrar apoyo a su radical forma de acción colectiva: las ocupaciones de tierra. Durante su período fundacional (1978-1984), la ocupación emerge como forma de acción fundamental, asumiendo la consigna de que LA OCUPACIÓN ES LA ÚNICA SOLUCIÓN. En un contexto de democratización general social, la ocupación asume ese proceso de forma radical, pues los campamentos que se establecen como resultado de aquella son "democráticamente autogestionados" (Löwy, 2003), articulando esta apropiación territorial con cierto régimen de vínculos y relaciones sociales.

La génesis del MOCASE se asocia al intento de desalojo que, en 1985, llevaron a cabo varias empresas contra unas 400 familias de Los Juríes, en Santiago del Estero. Esto provocó su movilización y organización, iniciando un movimiento campesino provincial (Durand, 2007). En su acta fundacional (en Durand, 2007: 35) se plantea como objetivo "buscar soluciones a problemas comunes, ser representantes de los campesinos ante las autoridades, apoyar las peticiones de cada una de las organizaciones que lo integran respetando su autonomía, promover la capacitación en cooperativismo y gremialismo, y mejorar la calidad de vida de los pequeños productores".

El MOCASE también se ha basado en el principio de que "debe alcanzar un peso político, pero manteniendo su independencia de los compromisos partidarios" (Cartilla del MOCASE, en VV AA, 2010: 51-52). Su reclamo de "justicia para todos"; la emergencia de los campesinos e indígenas como sujetos de reclamo y de derecho ciudadano y el enfrentamiento a un régimen de propiedad (propietarios) por un régimen de posesión (poseedores), resultan prácticas políticas relevantes del movimiento que van más allá de sus dinámicas internas y tienen un alcance social general, pues plantean "democratizar las relaciones sociales en base a la resignificación del acceso a la tierra como un derecho de ciudadanía" (Barbetta y Lapegna, 2002). 


\section{Material y método}

El estudio asume una perspectiva cualitativa, a partir del estudio comparativo de los dos movimientos sociales señalados — dada su relevancia analítica- y sin pretensiones de representatividad en términos estadísticos. Ante la diversidad inherente a los movimientos sociales resulta complejo realizar generalizaciones, por lo que el estudio solo pretende una aproximación a la cuestión que - esto sí- ofrece una perspectiva analíticamente significativa del tema en los movimientos sociales rurales latinoamericanos, derivada de la señalada relevancia de los dos movimientos incluidos en la investigación.

Este estudio comparativo se desarrolla mediante el análisis del discurso de entrevistas a miembros los movimientos sociales, así como de declaraciones y otros textos vinculados a estos actores colectivos. La perspectiva interpretativa del enfoque cualitativo se adecua al tema, a lo cual se añade la flexibilidad y contextualización que caracteriza este paradigma metodológico (Mason, 1996). El análisis de discurso se ha convertido en un importante método para la investigación en movimientos sociales (Taylor y Whittier, 2004), considerando que, como señala Castells (1999), éstos son lo que dicen ser.

Se han realizado un total de 17 entrevistas individuales a miembros de los dos movimientos ( 9 miembros del MST y 8 miembros del MOCASE), entre 2012 y 2013, en Brasil y Argentina, durante dos períodos de trabajo de campo efectuados en abril-mayo de 2012 y octubre-noviembre de 2013, respectivamente. Las entrevistas en profundidad se realizaron a partir de un guion temático abierto, como parte de un estudio sobre las interrelaciones entre individuo y colectividad en distintos movimientos sociales latinoamericanos y la emergencia de nuevas dinámicas de socialidad en sus experiencias. El perfil de los entrevistados incluyó a mujeres y hombres de diversas edades y tiempo de pertenencia al movimiento, así como a líderes y miembros en general. El perfil de los entrevistados - que tampoco fueron seleccionados siguiendo un criterio de representatividad estadística, sino a partir de su disponibilidad para participar en el estudio- se muestra en la Tabla 1.

Para el análisis de los dos niveles discursivos incluidos - el individual y el organizacional (Jonhston, 2004)—, se ha seguido una perspectiva que plantea la apertura del análisis del discurso al entramado de mediaciones que atraviesan una determinada visión del mundo, superando así un enfoque limitado al nivel estructural/textual (Alonso, 1998). Franzosi (1998: 527) propone un tránsito, en la búsqueda de sentidos como parte del análisis del discurso, desde las variables a los actores, que tome como recurso analítico las redes y secuencias narrativas en lugar de los modelos estadísticos de regresión.

Se superan así enfoques centrados en la búsqueda de lo significativo solo a partir de las palabras supuestamente más cargadas de significados (como los adjetivos), para incluir otras dimensiones discursivas, como la propia estructura y secuencias narrativas de los textos, los patrones de causalidades y temporalidades, o las propias 
relaciones sociales e interrogantes en torno a estas (Abbott, en Franzosi, 1998). En consecuencia, este enfoque permite articular —en el análisis de los discursos-, la indagación sobre los sentidos en torno a la territorialidad y la socialidad.

Tabla 1. Perfiles de los entrevistados

\begin{tabular}{|c|c|c|c|c|}
\hline Código & $\begin{array}{c}\text { Iniciales del } \\
\text { nombre }\end{array}$ & Rango de edad & Sexo & $\begin{array}{c}\text { Movimiento } \\
\text { Social }\end{array}$ \\
\hline E1 & AS & $40-50$ & H & MOCASE \\
\hline E2 & CG & $40-50$ & H & MOCASE \\
\hline E3 & MT & $40-50$ & M & MOCASE \\
\hline E4 & LL & $40-50$ & M & MOCASE \\
\hline E5 & PC & $30-40$ & H & MOCASE \\
\hline E6 & DC & $20-30$ & M & MOCASE \\
\hline E7 & JB & $20-30$ & M & MOCASE \\
\hline E8 & OD & $50-60$ & H & MOCASE \\
\hline E9 & NR & $40-50$ & H & MST \\
\hline E10 & AF & $20-30$ & M & MST \\
\hline E11 & AJ & $30-40$ & H & MST \\
\hline E12 & VG & $30-40$ & M & MST \\
\hline E13 & EA & $20-30$ & H & MST \\
\hline E14 & GG & $30-40$ & H & MST \\
\hline E15 & RL & $30-40$ & H & MST \\
\hline E16 & JS & $20-30$ & M & MST \\
\hline
\end{tabular}

Fuente: Elaboración propia.

\section{Movimientos sociales latinoamericanos: apropiación de la territorialidad desde nuevas socialidades}

La emergencia de los procesos de reterritorialización desde las prácticas de los movimientos sociales latinoamericanos articula dos dimensiones paralelas.

En primer lugar, la apropiación de ciertos "territorios sociales", en respuesta a los procesos de marginalización y exclusión de sus miembros en el ordenamiento social actual. Por territorio social se comprenderán todos aquellos espacios sociales 
susceptibles de ser objeto de propiedad, y que resultan sitios de anclaje de los sujetos en los procesos y relaciones sociales. Su expresión más directa y básica sería la tierra - sobre todo para los habitantes de zonas rurales-, pero también incluye, por ejemplo, la ciudad o las fábricas y empresas. Los sin tierra, los sin techo y los trabajadores desocupados, serían - respectivamente- los grupos desplazados de estos territorios sociales.

La segunda dimensión serían las comunidades virtuales que se gestan como parte de las experiencias comunicativas desplegadas por los movimientos. En sentido estricto, estaríamos en este caso frente a territorialidades exclusivamente "de sentido", pero que se proponen ser un correlato articulado armónicamente con los procesos de apropiación de territorialidades sociales "reales". Toda territorialidad social supone una territorialidad de sentido, dadas las asociaciones de valores, ideas, sentimientos, que se establecen como parte de aquella. Toda territorialidad constituye una forma de apropiación, en tanto síntesis objetivo-subjetiva de una relación efectivo-material y subjetiva (Dussel, 1985: 227).

La relación de los movimientos sociales con la territorialidad, en su sentido moderno, tiene uno de sus principios en su posicionamiento en relación con el Estadonación, los partidos políticos y la democracia representativa. Los movimientos aspiran a devenir espacios alejados de lo estatal, de gestación de un anti-poder o contrapoder, a cuyo interior emergería el cambio social (Zibechi, 2004). Esta perspectiva contraria a la territorialidad institucional moderna del Estado-nación, en el caso de los movimientos sociales de pueblos originarios, aparece siempre ligada a una dimensión cultural-identitaria, pues el territorio es entendido de manera multidimensional, como el soporte material y espiritual para la existencia de estos pueblos, con una significativa dimensión simbólica (Ojarasca, 2005). En consecuencia, sus reclamos incluyen la propiedad de estos territorios, pero también la protección del medio ambiente y la biodiversidad, el respeto de sus formas productivoeconómicas y de organización socio-territorial comunitarias.

Estos pueblos comprenden su relación con el entorno como un equilibrio entre las fuerzas de la naturaleza y su forma de vida. Su presencia configura una confrontación de territorialidades, en articulación con la interculturalidad que caracteriza el escenario latinoamericano (Bartolomé, 2010). Su comprensión de las interrelaciones entre sociedad y naturaleza cuestionan las territorialidades modernas impuestas $\mathrm{y}$, en particular, resisten y se oponen a un orden territorial que subordina el espacio al mercado (Seoane, 2006).

Este cuestionamiento al modelo de desarrollo dominante, alcanza incluso a los gobiernos que se autodefinen como representantes de los pueblos originarios - por ejemplo, el caso boliviano-, al oponerse a la deriva extractivista neodesarrollista de estos, que continúa asumiendo una relación utilitaria con el territorio y proponer, desde los movimientos, lo que se ha denominado como un giro ecoterritorial (Svampa, 2011). Las territorialidades vinculadas a los movimientos de pueblos originarios, también se asocian a unos saberes particulares, propios de estos colecti- 
vos, confirmando así la estrecha relación entre epistemes, espacio y poder, a la vez que muestra la relevancia del lugar - tanto social como geográfico- desde el que se enuncian los discursos (Porto-Gonçalves, 2009).

La territorialidad, para ellos, no es solo "un pedazo de suelo" sino "espacios que tienen sus propias fuerzas (gnen) en la tierra, ríos, esteros, bosques, animales, personas, las que se interrelacionan entre sí y permite un equilibro" (Seguel, 2006). Estos sentidos de territorialidad se encuentran ligados a formas de propiedad, economía y vida social comunitarias. Sus demandas incluyen que sus territorios de propiedad colectiva "no sean fraccionados y se prohíba de manera definitiva la titulación individual", así como "crear microempresas de economía comunitaria" (CONFENIAE, 2009).

Estas interconexiones territorialidad-cultura-cambio social-socialidad, resultan ejes explícitos en la agenda de los movimientos de pueblos originarios, que proponen "nuevas formas de convivencia humana y con la naturaleza" (Enlace Indígena, 2009). Para estos, la tierra "es mucho más que solo un pedazo de terreno para explotarlo con fines agrícolas u otros. [Es] su lugar de origen, su espacio sagrado y ritual" (Marcos, 2007: 325). La tierra es "la madre, es la depositaria de la cultura" donde "vive la historia y [...] los muertos" (Subcomandante Marcos, 2001), en una relación de continuidad con los sujetos, que resulta en una muy especial forma de colectividad humana, donde "no hay apenas individualidad. El mundo no está afuera, establecido en el exterior y separado de los seres sino que es y está a través de ellos. El yo no puede ser abstraído de su entorno" (Marcos, 2007: 326).

Pero esta interrelación entre propuestas alternativas de territorialidad y socialidad - que muestra la multiplicidad de las territorialidades, en este caso antagónicas, la Estatal y la de los movimientos, que conviven en un mismo espacio geográfico-, no solo es propia de los movimientos sociales de pueblos originarios. El análisis del MST y el MOCASE ofrece una perspectiva de esta articulación entre socialidad y territorialidad que no se plantea desde la recuperación o el mantenimiento de unos sentidos basados en la tradición o en unas cosmovisiones específicas - como ocurre en los movimientos indígenas-, sino en tanto configuración de los mismos a partir de las prácticas de estos actores colectivos.

\section{MST: tierra, reforma agraria y cambio social}

Desde su fundación, el MST asumió tres objetivos prioritarios (tierra, reforma agraria y transformación social), bajo la certeza de que "el mejor camino para dar continuidad a la lucha contra la pobreza y por una sociedad más justa era constituir un movimiento social amplio, de carácter nacional, independiente de los partidos, las iglesias, los Estado y gobiernos" (Stedile, 2004: 176). Los nuevos sentidos de territorialidad vinculados a su propuesta están estrechamente ligados no solo a un reordenamiento de la propiedad de la tierra —en el segundo país del mundo con 
mayor concentración de la propiedad agraria-, sino también a la gestación de un cambio social general, comenzando por sus propios miembros y comunidades.

Diversos estudios han analizado el proceso de gestación de una nueva construcción socioterritorial en las prácticas del MST. Entre ellos, se destacan los análisis de Bringel $(2007,2012,2014)$ acerca de la aportación de este movimiento en el proceso de configuración de nuevas geografías pos-coloniales, así como la importancia de la noción de lugar, en tanto que referencia política, para la comprensión de cuestiones como las interrelaciones entre movimientos sociales y gobiernos, en particular las prácticas espaciales de los primeros para influir en el debate político. Bringel y Falero (2008) han señalado la necesidad de una perspectiva interdisciplinar entre geografía y sociología para un análisis de la problemática del territorio y de la espacialidad de la política, que tiene una de sus expresiones más relevantes, precisamente, en la configuración de redes transnacionales de movimientos sociales latinoamericanos - como la Coordinadora Latinoamericana de Organizaciones del Campo (CLOC)—, entre los que se incluye precisamente el MST.

Desde una perspectiva local y nacional, la ocupación es la expresión más radical de la reterritorialización que propone el MST, vinculada a una proyección social de la cuestión rural en Brasil, pues "obliga a todos los sectores de la sociedad a manifestarse a favor o en contra" (Stedile, en Mançano, 2001: 113). El sentido de la territorialidad ligado a las ocupaciones, no transita por la simple extensión física de los territorios ocupados. Desde las primeras experiencias, su trascendencia no está dada "por el espacio geográfico, por el pedazo de tierra conquistado" sino por ser "una victoria" (Stedile, en Mançano, 2001: 14).

El contenido simbólico de las ocupaciones está estrechamente asociado a la tensión entre individualidad y colectividad. Son el punto de partida no solo hacia la obtención de un pedazo de tierra, sino hacia la gestación de una nueva apropiación territorial. Si bien inicialmente la principal motivación de una familia para participar en una ocupación es esencialmente económica - conquistar un pedazo de tierra-, luego esa reivindicación se transforma. Es un aprendizaje que incorpora la dimensión política, para finalmente llegar a la certeza de que "si una familia lucha solo por su pedazo de tierra y pierde el vínculo con el movimiento, entonces la lucha por la tierra no tiene futuro; querer cambiar la realidad es lo que hace que la lucha por la tierra se transforme en lucha por la reforma agraria" $(E 10,2013)^{1}$. Proponerse ir más allá de "esos movimientos que acaban cuando se conquistan la tierra, o que solo atienden a los intereses personales", es lo que "genera en los compañeros un nuevo sentido en la lucha por la tierra" (E16, 2013). Pero, al mismo

\footnotetext{
${ }^{1}$ Los textos de las entrevistas serán citados de esta forma: Código del entrevistado, año de realización de la entrevista.
} 
tiempo, "la conquista de la tierra es fundamental para avanzar en la radicalización y en la politización" de los individuos (E9, 2013).

En la acción colectiva del MST se distinguen dos momentos: el to - resultado de la ocupación- y en asentamiento — cuando ya se ha alcanzado la posesión de la tierra-. La relación de los sujetos con la territorialidad es diferente en ambos escenarios y ello está vinculado a las especificidades de los vínculos y relaciones sociales propios de cada uno de ellos. En los campamentos, las contradicciones internas se desdibujan, en una circunstancia de nueva-territorialidad-aúnpor-conseguir, que genera unidad frente a los enemigos externos (hacendados, policía). En el contexto de los asentamientos, en los sujetos que consideran lo colectivo necesario solo para el enfrentamiento externo, emergen actitudes de conflicto entre individualidad y comunidad, derivadas de las garantías asociadas a la nueva-territorialidad-ganada.

Bogo (2002: 156) compara la dialéctica de estos dos momentos. En el campamento "no hay propiedad, todavía se lucha por ella. Las relaciones sociales anteriores son cortadas y estructuradas de otra forma. [...] Las tareas son distribuidas de acuerdo con la importancia y la necesidad de las personas. [...] Hay una negación, primero, de la propiedad del latifundio, que pasa a ser propiedad de todos en su totalidad y, por eso, nadie individualmente es dueño". Pero luego, en el asentamiento "enseguida, viene el registro que individualiza, la distribución de la tierra que oficializa la separación entre las familias, desorganizándolas. Todas las relaciones, hábitos, vicios y prejuicios estaban apenas adormecidos en el período del campamento".

En el campamento, el contexto de resistencia y dificultades facilita que se cree "un sentimiento de comunidad, de alianza" (E11, 2013). La vivencia de las ocupaciones y del campamento es un momento fundamental de "la esencia del movimiento, que es juntar personas", porque es punto de partida para la configuración de "una conciencia social en las personas, de que es necesario transformar la sociedad y no solo luchar por un pedazo de tierra" (E17, 2012). Los sujetos destacan la necesidad de "generar una nueva sociedad en los asentamientos, organizar la producción, crear un modelo para la agricultura diferente" (E14, 2012).

Se subraya, precisamente, que esa nueva forma organizativa debe explorar nuevas formas de relaciones de producción colectivas, que superen la perspectiva de los movimientos campesinos tradicionales. Para ello, "tan importante como distribuir la tierra es distribuir el conocimiento" $(\mathrm{E} 13,2012)$, como parte de un proceso que no se limita a la propiedad de la tierra, sino a "la formación integral de toda nuestra base social. Queremos emanciparnos, pero también construir comunidades bonitas, donde pongamos en práctica otras relaciones sociales, basadas en la amistad, en la solidaridad, en el compañerismo" (E15, 2012).

En una etapa anterior, el MST asumió como principio la colectivización de las formas productivas y de la propiedad de la tierra, proponiendo que "había que colectivizar todo, $[\ldots]$ decíamos que cualquier persona para entrar en el movimiento 
tenía que ajustarse a esta forma" (E10, 2013). Sin embargo, luego se ha reconocido que este enfoque no era correcto, pues "tampoco se trata de, por decreto, colectivizar las cosas. Una práctica colectiva debe seguir un camino, por más difícil que sea, aunque necesite de más reuniones, de más experimentaciones", pues aunque resulta más difícil "al final da un buen resultado: que todos finalmente puedan participar y sentirse parte, dueños de aquello que construimos" (E12, 2012). En consecuencia, las formas de propiedad de la tierra en los asentamientos incluyen variantes totalmente individualizadas - aunque existan espacios, como la escuela o el puesto médico, de naturaleza colectiva-, otras en las cuales solo se realizan de manera colectiva determinados procesos productivos - como la comercialización- y, finalmente, experiencias completamente cooperativas.

Al analizar los desafíos de los asentamientos, los miembros del movimiento destacan precisamente la inherente vinculación entre gestación de nuevas formas productivas y nuevas socialidades: "nuestra lucha siempre tiene como objetivo construir un modelo alternativo de producción y de vivencia social, frente al agronegocio", una dimensión que se considera importante porque "no existe fuerza política sin una materialidad y, en nuestro caso, ella es fundamental en la organización de las escuelas, de las cooperativas y de la disputa del territorio" (E16, 2013). Para ello, el MST pone en práctica un conjunto de principios organizativos como la dirección colectiva, la igualdad de todos los participantes en las asambleas o la división de tareas.

Una de las prácticas más singulares del MST es la mística, en la cual también convergen un nuevo sentido de territorialidad y una socialidad diferente. Esta resulta expresión de su propósito de construir un cambio social que nace de juntar las personas con la tierra. No es cuestión solo de distribuirla entre nuevos propietarios, sino de "provocar cambios mayores entre la apropiación de la tierra y el respeto entre las personas", en "un retorno a los orígenes de la vida y de la formación social", como parte de un proceso solo posible sobre la base de la participación de "todos los seres humanos que participan en esta tarea de distribuir la tierra y sobre ella construir nuevas relaciones de poder" (Bogo, 2002: 153, 154-155).

Finalmente, también en los vínculos del movimiento con la sociedad en general, se ponen de manifiesto unas novedosas interrelaciones entre territorialidad y socialidad, que tienen como fundamento la oposición a un "tipo de planificación territorial privada y transnacional propuesto por instituciones financieras internacionales en complicidad con el Gobierno y el sector privado" (MST, 2007). El movimiento, en tal sentido, plantea una articulación de sus bases territoriales que propone una otra geografía distinta de la institucionalizada (Mançano, 2001: 43) y una proyección internacional del cambio social que trasciende - real y simbólicamente- las fronteras de las territorialidades nacional-modernas, incorporándose activamente a espacios como el FSM, la CLOC y Vía Campesina. 


\section{MOCASE: un nuevo modelo agrario y de país}

Desde sus inicios, el MOCASE se propuso no solo la resistencia ante el despojo de los territorios - esto es, frente a la desterritorialización real de ciertos grupos-: "no se trataba sólo de lograr la titularidad de la tierra, también se proponían transformar las relaciones sociales de producción" (Durand, 2007). Actualmente, reconocen que "la cuestión de fondo nuestra es la disputa por el modelo agrario. Planteamos no es solo la resistencia para que sobrevivan modelos culturales de producción de alimentos sino la propuesta de un modelo económico, derrotar a las transnacionales de la alimentación" (E1, 2012).

El MOCASE se enfrenta a la territorialidad del modelo sojero transgénico argentino que ha provocado el desplazamiento en la primera década del siglo XXI de unos 300 mil campesinos e indígenas (González, 2009). Un informe de Greenpeace (en González, 2009: 44), explica que los desmontes para la siembra de soja resultan en la pérdida de "su casa, su almacén, su farmacia y su cultura" para las comunidades campesinas e indígenas que tradicionalmente habitan y utilizan esos bosques argentinos.

Ese antagonismo entre dos modelos de territorialidades - tanto física como culturalmente-, tiene lugar en el marco de un imaginario social de la modernidad argentina, según el cual se concibe el campo como recurso productivo para financiar un estilo de vida urbano cuyo referente es Europa (Giarracca y Teubal, 2005). El enfrentamiento entre territorialidad-MOCASE y territorialidad-agronegocio, resulta el capítulo más reciente de esa relación histórica de subordinación: "En el año 1995, cuando empezó la soja, empezó el quilombo y empezaron los desalojos" $($ E6, 2012). De ahí que una comprensión compleja de este conflicto de modelos de territorialidad debe incluir no solo su dimensión espacial, sino también la simbólico-cultural, así como sus vínculos con un modelo agrario y un proyecto o imaginario social(izado) de nación.

Los sujetos establecen una clara oposición entre quienes están "adentro" - que pertenecen al espacio rural y "cuidamos la naturaleza"-, y los que vienen "de fuera", para "destruir la tierra, [...] vienen con máquinas, desmontan todo y después prenden fuego. Ni siquiera producen y si lo hacen es para afuera" $(E 8,2012)$. Esta apropiación de la tierra "no responde a la sociedad, sino a las grandes empresas y a las multinacionales", y tiene consecuencias negativas pues convierte "nuestros terrenos en verdaderos desiertos" (E4, 2012). En oposición, los entrevistados plantean que desean construir "una sociedad diferente. No queremos que uno trabaje para otro. Queremos trabajar y decidir juntos" $(\mathrm{E} 8,2012)$.

Esa socialidad alternativa está inherentemente vinculada a la apropiación del territorio por los campesinos y se ancla en tradiciones ligadas a formas de territorialidad y cultura campesina, como la minga y la ración. La ración "es algo así: un vecino carnea [sacrifica] una vaca, a aquel vecino le toca la pierna, al otro la espalda y así se la reparten. Mingar es trabajar solidariamente, es una cooperativa sin esa 
palabra" (E7, 2013). También en el MOCASE el sentido de lo comunitario se encuentra asociado a cierta religiosidad, al punto de considerar que la acción colectiva "está generando como una religión humana", con una inherente condición humana y colectiva, arraigada en la propia territorialidad: "Yo creo que Dios anda por el monte. Que nosotros somos dioses" (E1, 2012).

El hecho de que, en ciertas comunidades, se logre una propiedad colectiva de la tierra - fundamento de formas de producción cooperativa- es particularmente significativo, pues la propiedad resulta una dimensión crítica en los procesos de socialización y la que más conflictividades y resistencias genera en los mismos. Los miembros del movimiento reconocen que en algunos sujetos permanece la idea de propiedad individual de la tierra: "Nuestro desafío era cómo superar ese momento y la perspectiva del campesino de ver la propiedad de la tierra como un fin, de decir: «Yo quiero mi lote y punto»" (E5, 2013).

La territorialidad defendida por el MOCASE se expresa en tres dimensiones:

a) propiedad comunitaria de la tierra, fundada en la tradición, pues "aquí hay gente que vive hace muchos años pero no tiene demarcada hasta dónde llega su posesión porque fue una forma de vivir de conjunto, de toda la vida" (E2, 2012);

b) formas productivas colectivas y cooperativas, sustentadas en "la solidaridad, la colectividad, el trabajo en conjunto. Porque lo que no tiene uno, el otro lo puede tener" (E8, 2012); y

c) las dinámicas, las estructuras y las formas de organización del movimiento, fundadas en el principio de que "los dirigentes no mandan; aquí manda la organización, ellos solo representan" (E6, 2012).

Esta configuración de una nueva socialidad anclada en la territorialidad, está asociada al crecimiento individual y colectivo de los sujetos. Los miembros del movimiento vinculan este proceso a una concientización que lleva a trascender una perspectiva del territorio como cuestión que se limita a "resolver el título de propiedad o vender mi cabrito y punto. Esa es una de las tantas cosas que hay que ver y por las que hay que luchar, pero no es la solución" (E3, 2013). La cuestión de la tierra es un primer elemento, pues "el pequeño productor debe tener la seguridad del terreno donde vive"; el segundo, "el tema cooperativo", pero "después hay toda una lucha, que es nuestro gran objetivo: ir hacia una reforma agraria" (E4, 2012).

La diferencia entre el sentido de la territorialidad como propiedad individual y el espíritu del movimiento, lo sintetiza un testimonio: "Hay muchos que dicen 'yo tengo mi terreno y quiero mi título de propiedad y se acabó: ese es mi objetivo'. Pero nuestra lucha no termina así" (E2, 2012). Las individualidades tienen una especial relación con su territorio - en tanto que espacio de socialización-, explícita en el giro lingüístico de la persona desde la cual hablan los sujetos: así, un entrevistado explica que "esta es mi posición, esta es mi casa, es nuestro territorio y 
vamos a defenderlo" (E6, Entrevista, 2012). A diferencia de otros elementos, el territorio no es "mío" sino "nuestro".

El concepto de territorio es integral: "es donde estamos viviendo nosotros, donde tenemos los animales, todo, la naturaleza..." (E2, 2012). Es también las tradiciones, "lo que va saliendo [en los procesos de aprendizaje], que aprendemos recién nosotros, [pero] que viene del tiempo, de antes" (E7, 2013). Así, por ejemplo, en el programa de la Escuela de Agroecología del MOCASE existe una asignatura sobre Territorio, en la cual los alumnos participan en la recuperación de esos conocimientos que forman parte del territorio. Las individualidades van aportando a la propia comprensión de la territorialidad: su aportación en la socialización (educativa) va configurando y enriqueciendo la propia noción de territorio.

\section{Conclusiones}

El análisis de los dos movimientos latinoamericanos rurales seleccionados para el estudio, muestra que, en ambos casos, la emergencia de estos actores colectivos está vinculada a un proceso de desterritorialización que, si bien sobre todo en el caso del MOCASE - dado su mayor vinculación con tradiciones de pueblos originariostiene un componente cultural-identitario, es también un proceso efectivo, en el sentido material, ligado al despojo del territorio a los sujetos, como resultado de procesos de modernización agrícola y extensión del modelo de agronegocio. En tal sentido, estos movimientos no serían el resultado de lo que Haesbaert (2007) denomina el "mito de la desterritorialización", sino que están vinculados a un proceso real de desplazamiento de los sujetos de sus territorios, en el contexto de una región marcada por una profunda desigualdad y en la cual la acción colectiva, si bien incluye de manera creciente demandas de carácter identitario y cultural, está inherentemente asociada a esta desigualdad (Eckstein, 2001; Eckstein y WickhamCrowley, 2003).

Al respecto, los nuevos sentidos de la territorialidad propuestos por ambos movimientos asumen posturas contrahegemónicas frente al modelo de la modernidad capitalista, en particular su propuesta neoliberal, configurando un escenario de multiplicidad territorial, en este caso, de dos territorialidades antagónicas que coexisten en el mismo espacio —os respectivos Estados-nación-. Esta oposición se expresa en sus dimensiones espacial y simbólica. Esta última es significativa, en tanto aparece vinculada de forma inherente a los sentidos que acompañan las nuevas apropiaciones de la territorialidad. Esos sentidos alternativos sobre el territorio que tienen como objetivo trascender un enfoque centrado en la propiedad individual de la tierra-, se configuran en los procesos de socialización vividos en las experiencias de cada movimiento. Socialidad y territorialidad se articulan en la continuidad de las interrelaciones individuo-naturaleza e individuo-individuo, una convergencia 
que en tanto en el MST como en el MOCASE se considera imprescindible al interior de los procesos de cambio social.

El proceso que tiene lugar en cada movimiento, en las interrelaciones entre reapropiación territorial y configuración de nuevas socialidad, es complejo y se caracteriza por las mediaciones mutuas y la interdependencia. La emergencia de una socialidad opuesta al individualismo se fundamenta, inicialmente, en una determinada acción colectiva para alcanzar/mantener cierta territorialidad social (por ejemplo, en las ocupaciones del MST). Más tarde, esta socialidad emergente, que se comienza a gestar desde la acción colectiva, tendrá como escenario de consolidación y condición de posibilidad a una apropiación territorial efectiva - el asentamiento, en el caso del MST; la cooperativa, en el MOCASE- que permita la puesta en práctica de formas y relaciones comunitarias de poder en las cuales se geste el cambio social.

Es una relación dialéctica donde la acción colectiva es condición para lograr - $\mathrm{o}$ mantener - una apropiación de una territorialidad que, a su vez, deviene lugar de asentamiento para la consolidación de una nueva socialidad, que debe ser complemento de la gestación de un sentido otro de territorialidad. Por consiguiente, esta socialidad alternativa comunitaria no solo media en la configuración de sentidos de territorialidad; también coadyuva en el propósito de obtener/mantener una cierta espacialidad física. El análisis de ese proceso en estos dos movimientos sociales, mostraría una singular dinámica de reterritorialización, que en este caso se entiende como reapropiación del territorio, tanto en su sentido material (ocupación o mantimiento de la tierra) y simbólico (vinculado a los sentidos otorgados a la relación con el territorio, que incluyen las interrelaciones entre individuos y colectivo). Ello es coherente con la perspectiva sobre la apropiación que plantea Dussel (1985), en tanto que síntesis objetivo-subjetiva.

La articulación entre nuevas territorialidades sociales y de sentido que observamos en ambos movimientos aparece mediada por la nueva socialidad emergente, mientras la solución de continuidad entre acción colectiva inicial y configuración de socialidades alternativas, se afinca en las prácticas desarrolladas en el territorio apropiado. La complejidad del proceso radica en que cada uno de estos momentos presenta sus tensiones específicas -expresadas, por ejemplo, en las diferencias expuestas entre las dinámicas colectivas que se vivencian en los campamentos y los asentamientos, en el caso del MST- Pero si bien ambos movimientos sociales asumen que el escenario primario del cambio social son sus cas — confirmando así lo planteado, entre otros, por Zibechi (2004)—, una transformación como la que plantean estos, necesita de una ampliación de sus alcances, más allá de sus fronteras espaciales, es decir, de sus territorios. Estas socialidades que se despliegan como parte de la apropiación territorial en los movimientos, necesitan un diálogo con la sociedad, no solo debido a la cuestión de la espacialidad, sino porque su propuesta última apunta a proyectos de transformación social en sentido general, y no solo para los sujetos que participan en los movimientos. 
Dos dimensiones que median, tanto en el MST como el MOCASE, las interrelaciones entre socialidad y territorialidad son la comunicativa y la ritual.

$\mathrm{Al}$ interior de los movimientos y en su vinculación con lo social, la comunicación es uno de los ejes de articulación/continuidad entre apropiación de territorialidad y emergencia de socialidades. Es una de las dimensiones por las cuales transita la gestación de una socialidad alternativa, la concienciación de los sujetos y la socialización general del sentido alternativo de territorialidad y socialidad propuesto. La exploración de nuevas formas de propiedad colectiva territorial requiere de unas dinámicas comunicativas y organizativas que garanticen la armonía entre ambas condiciones, mediante asambleas, mesas, fórmulas de dirección colectiva, etc.

Los espacios de comunicación horizontal y participativa, hacen que, mientras las territorialidades tradicionales suponen unas socialidades mediadas por jerarquías - las relaciones entre distintos Estados-naciones están normadas y jerarquizadas-, en los movimientos se proponen socialidades no mediadas por jerarquías territoriales, y relaciones de territorialidad no mediadas por jerarquías de socialidad. Ello se corresponde, además, con el espíritu global de los movimientos sociales, que se expresa en una ruptura no solo simbólica sino también real con la territorialidad del Estados-nación.

Otra dimensión articulante, en ambos movimientos, entre territorialidades y socialidades es la ritualidad. Ligada a lo espiritual y emocional, se manifiesta en la mística del MST y en la novedosa religiosidad del MOCASE y se expresa en la complementariedad de las transformaciones en los vínculos entre individuos y los de estos con el territorio y la naturaleza. En las ritualidades convergen dos circunstancias vinculadas a la socialidad y la territorialidad: se trata de dinámicas esencialmente colectivas que, en sus manifestaciones, ponen en práctica ciertas apropiaciones de lugares, objetos, o hechos, (re)simbolizándolos. Tales objetos, hechos o lugares, están frecuentemente vinculados al territorio y a la producción que se realiza en el mismo (por ejemplo, instrumentos de trabajo y productos, en el caso de la mística del MST). Estaríamos frente a una ritualidad socializada que es, al mismo tiempo, una territorialidad ritualizada.

Los movimientos sociales analizados proponen una apropiación de la territorialidad - y de los sentidos ligados a ésta - , marcada por un signo alternativo respecto al proyecto de la modernidad capitalista - y en particular su modelo neoliberal一, que se sustenta en la emergencia de una nueva socialidad. Frente a las concepciones que vinculan los procesos de desterritorialización a la posibilidad ampliada de las socialidades - TIC mediante- y su cuestionamiento de conceptos antes fundamentados en la convivencia física, o que plantean una perspectiva de estos ligada sobre todo al incremento de la movilidad y al hibridismo identitario-cultural (Haesbaert, 2013), el análisis realizado muestra que, en el caso de estos dos movimientos sociales, la desterritorialización —además de una dimensión efectiva (desplazamiento de los sujetos y despojo de las tierras)—, también puede ser entendida como un proceso ligado a ciertas formas de socialidad, implícitas en modelos de territorialidad 
como el del agronegocio. Del mismo modo, otras dinámicas de socialidad antagónicas al individualismo neoliberal, se asocian a los procesos de apropiación territorial que se enfrentan a aquellos procesos de desterritorialización. Ello muestra, tanto en el MST como en el MOCASE, la articulación entre configuración de nuevas socialidades y apropiaciones de territorialidades, como parte de un proyecto de cambio a la vez individual y colectivo, que incluye de forma inherente la relación con el territorio y la naturaleza.

\section{Bibliografía}

Achkar, Marcel (2003) "Espacio y territorio en el contexto del debate modernidad/posmodernidad", en T. Linck y C. Schiavo (coord.) Globalización y territorio. Montevideo: Nordan, 39-49.

Agnew, John, y Oslender, Ulrich (2010) "Territorialidades superpuestas, soberanía en disputa: lecciones empíricas desde América Latina”. Tabula Rasa, núm. 13, 191-213.

Alonso, Luis (1998) La mirada cualitativa en sociología. Madrid: Editorial Fundamentos.

Anderson, Benedict (1991) Imagined Communities: Reflections on the Origin and Spread of Nationalism. London: Verso.

Barbetta, Pablo, y Lapegna, Pablo (2002) "Tierra y ciudadanía: el caso del Movimiento Campesino de Santiago del Estero (MOCASE), Argentina". Realidad Económica [Puesto en línea el 2 de septiembre de 2002. URL: $<$ http://cdi.mecon.gov.ar/biblio/docelec/MU1735.pdf $>$. Consultado el 23 de julio de 2011].

Bartolomé, Miguel (2010) "Interculturalidad y territorialidades confrontadas en América Latina". Runa, vol. 31, núm. 1, 9-29.

Bogo, Ademar (2002) O vigor da mística (Cuaderno de Cultura $n^{\circ} .2$, Movimento dos Trabalhadores Rurais Sem Terra). São Paulo: Associação Nacional de Cooperação Agrícola.

Bozzano, Horacio (2000) Aportes para una teoría territorial del ambiente. Buenos Aires: Espacio.

Brenner, Neil (1999) "Globalisation as Reterritorialisation: The Re-scaling of Urban Governance in the European Union". Urban Studies, vol. 36, núm. 3, 431-451.

Bringel, Breno (2007) "O lugar nos movimentos sociais e o lugar da geografia na teoria dos movimentos sociais". Boletim Goiano de Geografia, vol. 27, núm. 2, 35-49.

Bringel, Breno (2012) "El lugar también importa. Las diferentes relaciones entre Lula y el MST". Revista Nera, núm. 9, 28-48. 
Bringel, Breno (2014) "Ativismo transnacional, o estudo dos movimentos sociais e as novas geografias pós-coloniais". Estudos de Sociologia, vol. 2, núm. 16, 185215.

Bringel, Breno, y Falero, Alfredo (2008) "Redes transnacionais de movimentos sociais na América Latina e o desafio de uma nova construção socioterritorial". Caderno CRH, vol. 21, núm. 53, 267-286.

Brünner, José (1998) Globalización cultural y posmodernidad. Santiago de Chile: Fondo de Cultura Económica.

Castells, Manuel (1999) La era de la información. Volumen 2: El poder de la identidad. Madrid: Alianza Editorial ( $2^{\mathrm{a}}$ ed).

CONFENIAE (Confederación de Nacionalidades Indígenas de la Amazonía Ecuatoriana) (2009) "Resoluciones del Congreso de Unidad, Reconstitución y Fortalecimiento". Confeniae [Puesto en línea el 31 de mayo de 2009. URL: $<$ http://www.confeniae.org.ec/>. Consultado el 18 de noviembre de 2014].

Durand, Patricia (2007) El Movimiento Campesino de Santiago del Estero. Buenos Aires: Editorial Último Recurso.

Dussel, Enrique (1985) La producción teórica de Marx: un comentario a los Grundrisse. México: Siglo XXI Editores.

Eckstein, Susan E. (2001) "Power and Popular Protest in Latin America", en S. E. Eckstein y M. A. G. Merino (eds.) Power and popular protest:Latin American social movements. Berkeley y Los Angeles: University of California Press, 1-60.

Eckstein, Susan E., y Wickham-Crowley, Timothy P. (2003) "Struggles for social rights in Latin America: Claims in the arenas of subsistence, labor, gender and ethnicity, en S. E. Eckstein y T. P. Wickham-Crowley (eds.) Struggles for Social Rights in Latin America. New York y London: Routledge, 1-56.

Enlace Indígena (2009) "Diálogo de Alternativas y Alianzas de los Movimientos Indígenas, Campesinos y Sociales del Abya Yala". Movimientos.org [Puesto en línea el 3 de mayo de 2009. URL: $<\mathrm{http}$ ://movimientos.org/enlacei/show_text.php3?key=13864>. Consultado el 29 de noviembre de 2013].

Entrena Durán, Francisco (1999) "La desterritorialización de las comunidades locales y su creciente consideración como unidades de desarrollo". Revista de desarrollo rural y cooperativismo agrario, núm. 3, 29-42.

Franzosi, Roberto (1998) "Narrative Analysis-Or Why (And How) Sociologists Should be Interested in Narrative". Annual Review of Sociology, vol. 24, 517554.

García Canclini, Néstor (1989) Culturas híbridas. Estrategias para entrar y salir de la modernidad. México: Grijalbo.

García Canclini, Néstor (2001) Consumidores y ciudadanos. Conflictos multiculturales de la globalización. Madrid: Grijalbo. 
Giarracca, Norma, y Teubal, Miguel (coords.) (2005) El campo argentino en la encrucijada. Estrategias y resistencias sociales, ecos en la ciudad. Buenos Aires: Alianza Editorial.

González, Rodolfo (2009) ¡Adentro! Millonarios, chacareros y perdedores en la nueva Argentina rural. Buenos Aires: Marea Editorial.

Haesbaert, Rogério da (2007) O mito da desterritorializção: do "fim dos territórios" á multiterritorialidade. Rio de Janeiro: Bertrand Brasil.

Haesbaert, Rogério da (2013) "Del mito de la desterritorialización a la multiterritorialidad". Cultura y representaciones sociales, vol. 8, núm. 15, 9-42. [Puesto en línea en $2013 . \quad$ URL: $<$ http://www.revistas.unam.mx/index.php/crs/article/view/41590>. Consultado el 22 de abril de 2015].

Harnecker, Marta (2002) Sin Tierra. Construyendo movimiento social. Madrid: Siglo XXI Editores.

Herner, María (2009) "Territorio, desterritorialización y reterritorialización: un abordaje teórico desde la perspectiva de Deleuze y Guattari”. Huellas, núm. 13, $158-171$.

Jonhston, Hank (2004) "Verification and Proff in Frame and Discourse Analysis", en B. Klandermans y S. Staggenborg (eds.) Methods of Social Movement Research. Minneapolis: University of Minnesota Press, 61-91.

Krause, Mariane (2001) "Hacia una redefinición del concepto de comunidad. Cuatro ejes para un análisis crítico y una propuesta". Revista de Psicología, núm. 2. [Puesto en línea en $2001 . \quad$ URL: $<$ http://rehue.csociales.uchile.cl/psicologia/publica/PSICO\%202.pdf $>$. Consultado el 29 de noviembre de 2013].

LaFeber, Walter (1999) Michael Jordan and the New Global Capitalism. New York: Norton \& Company.

Lopes de Souza, Marcelo (1995) "O território: sobre espaço e poder, autonomia e desenvolvimento", en I. E. de Castro, P. C. da Costa Gomes y R. Lobato (orgs.) Geografia: conceitos e temas. Río de Janeiro: Bertrand, 120-143.

Löwy, Michael (2003) "Orígenes socio-religiosos del Movimiento de Trabajadores Rurales Sin Tierra del Brasil". Revista América Libre, núm. 20. [Puesto en línea en 2003.

URL: $<$ http://www.nodo50.org/americalibre/anteriores/20/lowy20.htm $>$. Consultado el 23 de marzo de 2011].

Mançano, Bernardo (2001) Brava gente. La lucha del MST y la lucha por la tierra en Brasil. Entrevista a Joao Pedro Stedile. La Habana: Editorial Caminos.

Marcos, Silvia (2007) "Identidades en transformación: las prácticas feministas en el movimiento de mujeres indígenas", en Grupo América Latina: Filosofía Social y Axiología (comp.) Diversidad, identidad y articulación: construyendo alternativas desde los movimientos sociales. La Habana: Editorial de Ciencias Sociales, 293-333. 
Mason, Jennifer (1996) Qualitative Researching. London: Sage.

MST (2007) "No pasarán sobre el pueblo del Madera". Movimientos.org. [Puesto en línea el 22 de marzo de 2007. URL: <http://movimientos.org/cloc/mstbr/show_text.php3?key=9520>. Consultado el 12 de noviembre de 2013].

Ojarasca (2005) "La ocupación de territorios indígenas: política de Estado en América Latina". Suplemento mensual del periódico La Jornada, núm. 97. [Puesto en línea el 16 de mayo de 2005. URL: $<$ http://www.jornada.unam.mx/2005/05/16/oja97-americalat.html $>$. Consultado el 29 de noviembre de 2013].

Porto-Gonçalves, Carlos Walter (2009) "De Saberes y de Territorios: diversidad y emancipación a partir de la experiencia latino-americana". Polis (Santiago), vol. 8 , núm. 22, 121-136.

Raffestin, Claude (1993) Por uma geografia do poder. São Paulo: Atica.

Riechman, Jorge, y Fernández Buey, Francisco (1995) Redes que dan libertad. Introducción a los nuevos movimientos sociales. Barcelona: Editorial Paidós.

Sack, Robert (1986) Human territoriality. Its theory and history. Cambridge: Cambridge University Press.

Sader, Emir (2008) “América Latina, ¿el eslabón más débil?”. New Left Review, núm. 52, 5-28.

Santos, Milton (1994) "O retorno do territorio", en Territorio, Globalização $e$ Fragmentação. Sao Paulo: HUCITEC, 15-21.

Seguel, Alfredo (2006) "Conflictos socio-ambientales, consecuencias en los territorios y los derechos humanos en la Araucanía". Mapuexpress. Informativo Mapuche [Puesto en línea el 26 de octubre de 2006. URL: $<$ http://www.mapuexpress.net/?act=publications\&id=453>. Consultado el $15 \mathrm{de}$ noviembre de 2014].

Seoane, José (2006) "Movimientos sociales y recursos naturales en América Latina: resistencias al neoliberalismo, configuración de alternativas". Sociedade e Estado, vol. 21, núm. 1, 85-107.

Seoane, José; Taddei, Emilio, y Algranati, Clara (2006) "Las nuevas configuraciones de los movimientos populares en América Latina", en A. Borón y G. Lechini (comps.) Política y movimientos sociales en un mundo hegemónico. Lecciones desde África, Asia y América Latina. Buenos Aires: CLACSO, 227-250.

Stedile, João Pedro (2004) "MST 20 años: el significado de una celebración". El Otro Derecho, núm. 31-32, 175-179.

Subcomandante Marcos (2001) "La cuarta guerra mundial". Motion Magazine [Puesto en línea el 26 de octubre de 2001. URL: $<$ http://www.inmotionmagazine.com/auto/cuarta.html $>$. Consultado el 29 de noviembre de 2013].

Svampa, Maristella (2011) "Extractivismo neodesarrollista y movimientos sociales: ¿Un giro ecoterritorial hacia nuevas alternativas", en M. Lang y D. Mokrani (comps.) Mas allá del desarrollo. Quito: Ediciones ABYA, 185-216. 
Tarrow, Sydney (1994) El poder en movimiento: Los movimientos sociales, la acción colectiva y la política. Madrid: Alianza Universidad.

Taylor, Verta, y Whittier, Nancy (2004) "Analytical Approaches to Social Movements Culture: The Culture of the Women's Movement", en H. Jonhston y B. Klandermans (eds.) Social Movements and Culture. Minneapolis: University of Minnesota Press, 163-187.

Tilly, Charles (1995) Popular Contention in Great Britain, 1758-1834. Cambridge: Harvard University Press.

VV AA (2010) Memoria de los orígenes de la Central Campesina de Pinto. Santiago del Estero: MOCASE-VC.

Zibechi, Raúl (2003) "Los movimientos sociales latinoamericanos: tendencias y desafíos", OSAL: Observatorio Social de América Latina, núm. 9, 185-188.

Zibechi, Raúl (2004) "El otro mundo es el «adentro» de los movimientos sociales". América Latina en movimiento, núm. 386, 49-52. 